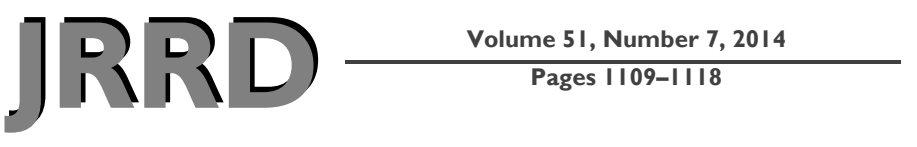

\title{
Novel mouse model of spinal cord injury-induced heterotopic ossification
}

\author{
Heejae Kang, BA; ${ }^{1}$ Alexis B. C. Dang, MD; ${ }^{1-2}$ Sunil K. Joshi, BA; ${ }^{1-2}$ Bernard Halloran, PhD; ,3 $^{3}$ Robert Nissen- \\ son, PhD; $;^{1,3}$ Xia Zhang, MD; ${ }^{4}$ Jianan Li, MD; ${ }^{4}$ Hubert T. Kim, MD, PhD; ${ }^{1-2}$ Xuhui Liu, MD ${ }^{1-2 *}$ \\ ${ }^{1}$ San Francisco Department of Veterans Affairs Medical Center, San Francisco, CA; Departments of ${ }^{2}$ Orthopaedic Sur- \\ gery and ${ }^{3}$ Medicine, University of California at San Francisco, San Francisco, CA, ${ }^{4}$ Department of Rehabilitation \\ Medicine, First Affiliate Hospital of Nanjing Medical University, Nanjing, Jiangsu Province, China
}

\begin{abstract}
Heterotopic ossification (HO) develops in about $20 \%$ to $30 \%$ of patients with spinal cord injury (SCI) and significantly impairs their rehabilitation. There is no effective prevention or treatment for this condition at this time. Our current understanding of its etiology and pathophysiology is limited partially due to the lack of clinically relevant animal models. In this study, we report a novel mouse model of SCI-induced HO by administering a subthreshold dose of bone morphogenetic protein (BMP)-2 to muscles in mice after SCI. Microcomputed tomography scanning showed that an intramuscular injection of 0.25 micrograms of BMP-2 causes significant $\mathrm{HO}$ in mice with SCI but not in control (sham surgery) mice. Our analysis of gene expression showed significantly increased BMP signaling in quadriceps following SCI, suggesting that BMP signaling may play a role in SCI-induced HO. Administering 0.25 micrograms of BMP-2 to the front arms of the mice with SCI also results in the development of significant $\mathrm{HO}$ but not in control mice. This suggests that SCI causes a systematic osteogenic effect, which is not limited to paralyzed limbs. This novel mouse model will serve as a powerful tool in exploring the molecular mechanisms of SCI-induced HO, which may lead to novel treatment for this disease.
\end{abstract}

Key words: bone morphogenetic protein-2, heterotopic ossification, injury, microcomputed tomography, mouse model, muscle, rehabilitation, spinal cord injury, trauma, Veterans.

\section{INTRODUCTION}

Heterotopic ossification (HO) is defined as the abnormal deposition of mature, lamellar bone in nonosseous tissues, especially in skeletal muscle [1]. The incidence of $\mathrm{HO}$ in injured military personnel returning from Operation Iraqi Freedom, Operation Enduring Freedom, and Operation New Dawn in the Middle East has been reported to be much higher than in the civilian population [2-4]. The pathogenesis of HO remains unknown to date. Clinically, $\mathrm{HO}$ is most commonly observed in patients with limb trauma or certain types of orthopedic surgeries, such as total hip arthoplasty. However, HO is also seen following central nervous system (CNS) injuries with or without limb injuries [5-6]. Previous studies have reported that about 10 to 37 percent of patients with traumatic

\footnotetext{
Abbreviations: $\mathrm{BMP}=$ bone morphogenetic protein, $\mathrm{BV}=$ bone volume, $\mathrm{CNS}=$ central nervous system, microCT $=$ microcomputed tomography, $\mathrm{H} \& \mathrm{E}=$ hematoxylin and eosin, $\mathrm{HO}=$ heterotopic ossification, $\mathrm{RNA}=$ ribonucleic acid, RT$\mathrm{PCR}=$ reverse transcript polymerase chain reaction, $\mathrm{SCI}=$ spinal cord injury, $\mathrm{T}=$ thoracic, $\mathrm{VA}=$ Department of Veterans Affairs. *Address all correspondence to Xuhui Liu, MD; San Francisco VA Medical Center, 4150 Clement St, Building 2, Room 639, San Francisco, CA 94121; 415-221-4810, ext 2742; fax: 415-750-2181. Email: Liux@orthosurg.ucsf.edu http://dx.doi.org/10.1682/JRRD.2014.01.0019
} 
brain injury [7-9] and about 20 to 30 percent of patients with spinal cord injury (SCI) [10-11] develop HO after CNS injuries.

A recent study showed that in the years 2005 to 2009 , SCI accounted for 11.1 percent of the casualties of combat injuries in the conflicts in Afghanistan and Iraq [12]. Passive and active motion is a critical part in the rehabilitation strategy for those veteran patients. HO severely restricts joint movement, causes pain and soft tissue infections, and significantly impairs the rehabilitation of patients with SCI. HO is difficult to prevent and, once developed, extremely difficult to treat. Current treatment options are limited to gross surgical excision, radiation therapy, and nonsteroidal anti-inflammatory drugs. Unfortunately, these treatment options have been unsuccessful in preventing or curing HO. Surgical excision has recurrence rates as high as 25 percent, requiring further surgery [3,13-14]. Likewise, these treatments may cause additional morbidity and mortality to patients. Thus, a more potent treatment strategy is needed to prevent and treat $\mathrm{HO}$ for patients with SCI.

Our poor understanding of the molecular mechanisms of SCI-induced HO is partially due to the lack of clinically relevant animal models, especially murine models. Due to the existing pool of transgenic and knockout mice, murine disease models have been widely used to investigate disease mechanisms and develop treatment strategies. However, there is no SCI-induced mouse $\mathrm{HO}$ model available at this time. In contrast to humans, mice do not develop HO spontaneously after complete or incomplete SCI. Previous studies have shown that bone morphogenetic proteins (BMPs) can sufficiently induce HO in mice [15]. Based on this finding, we have recently developed a mouse model of trauma-induced $\mathrm{HO}$ by combining intramuscular injection of a small dose of BMP-2 with focal muscle injury [16]. However, this model does not include an SCI component. In this study, we sought to develop a novel mouse model of SCI-induced HO by combining SCI with a subthreshold dose of BMP-2 in the muscle.

\section{METHODS}

\section{Spinal Cord Injury Animal Model}

Three-month-old male C57/BL6 mice (The Jackson Laboratory; Sacramento, California) were used in this study. Mice were randomly divided into two groups, SCI and control. Mice in the SCI group underwent a dorsal midthoracic laminectomy with spinal cord contusion using a modified Allen weight drop method that has been validated by other studies [17-19]. The injury was induced by dropping a $35 \mathrm{~g}$ stainless steel rod onto the exposed spinal cord at the thoracic (T)10 level with a penetrating depth of $1.8 \mathrm{~mm}$ from a height of $50 \mathrm{~mm}$, generating a complete paraplegia. Mice in the control group underwent sham surgery, in which the spinal process of T10 was removed to simulate focal soft tissue and bony injuries in the SCI group. The wound was then closed in layers with sutures. Animals were under anesthesia with 1 to 4 percent isoflurane in oxygen inhalation during all procedures. In total, 39 mice were used in this study (24 for HO induction and 15 for gene expression study). Based on the result from our pilot study, under the assumption $\alpha=0.05$ and $\beta=0.80$, a power analysis suggested that a sample size of three was needed in each group $(n=3)$. The Table summarizes the animal groups.

\section{Induction of Heterotopic Ossification with Bone Morphogenetic Protein-2}

In vivo controlled release of BMP-2 was achieved by mixing recombinant human BMP-2 (Medtronic Sofamor Danek USA Inc; Memphis, Tennessee) with a heparinchitosan ionic complex, in the form of a hydrogel (ExThera AB; Stockholm, Sweden), which has been proven to successfully induce $\mathrm{HO}$ in rats [20]. Mice in both the SCI and control groups were further randomly divided into three subgroups, receiving $0,0.25$, and $0.50 \mu \mathrm{g}$ of BMP-2 injection, respectively ( $n=4$ in each group). In brief, $10 \mu \mathrm{L}$ of heparin-chitosan hydrogel with different doses of BMP-2 was injected into the quadriceps muscle in the hind limbs with a microsyringe immediately after SCI or sham surgery before the animal woke up from anesthesia. In order to test whether SCI-induced HO is limb-paralysis-dependent, we injected the $0 \mu \mathrm{g}$ (vehicle only) and a low dose of $0.25 \mu \mathrm{g}$ BMP-2 into the triceps muscle in the bilateral fore limbs. The mice were allowed to move freely about their cages after injection. Food gel pack and water were placed on the floor in the cages within the reach of animals.

\section{Microcomputed Tomography Analysis}

Animals were sacrificed $14 \mathrm{~d}$ after surgery. The midthoracic spine, fore limbs, and hind limbs were harvested and fixed in 10 percent phosphate-buffered saline formalin for $24 \mathrm{~h}$. The fore limbs and right limbs were then 
Table.

Animal grouping.

\begin{tabular}{|c|c|c|c|c|}
\hline Group & Treatment & Time Point (d) & BMP-2 Dose ( $\mu \mathrm{g})$ & No. of Animals \\
\hline \multirow[t]{6}{*}{ BMP-2 Injection Group } & SCI & 14 & $0^{*}$ & 4 \\
\hline & & & 0.25 & 4 \\
\hline & & & 0.50 & 4 \\
\hline & Sham Surgery & 14 & $0^{*}$ & 4 \\
\hline & & & 0.25 & 4 \\
\hline & & & 0.50 & 4 \\
\hline & Sham Surgery & 3 & - & 3 \\
\hline & & 7 & - & 3 \\
\hline & No Treatment & 0 & - & 3 \\
\hline Total No. of Animals & - & - & - & 39 \\
\hline
\end{tabular}

dehydrated and stored in 75 percent ethanol. Microcomputed tomography (microCT) analysis was conducted using a Viva CT40 (Scanco Medical AG; Brüttisellen, Switzerland). For the fore limbs, a scoutview image was taken for each sample without segmental scanning. For hind limbs, scanning was conducted with the isotropic voxel size of $10.5 \mu \mathrm{m}$ and the X-ray energy of $55 \mathrm{kV}$. A global threshold, set at 245 in the per mille unit or 376 $\mathrm{mg}$ of hydroxyapatite/centimeters-cubed, was applied to distinguish mineralized from soft tissue. Ossification was assessed by quantifying the total amount of mineralized tissue and the degree of bone mineralization (segmented density).

\section{Histology}

After fixation, the left hind limbs and spine samples were decalcified using a 10 percent buffered ethylenediaminetetraacetic acid solution $(\mathrm{pH}=8.0)$ for $2 \mathrm{wk}$ on a shaker. Decalcified samples were embedded in paraffin, sectioned at $7 \mu \mathrm{m}$ of thickness. Sections were stained with hematoxylin and eosin (H\&E) for morphometric evaluation.

\section{Quantitative Polymerase Chain Reaction}

As a separate group, six mice underwent SCI and six underwent sham surgery without BMP-2 injection. Mice were sacrificed at days 3 and 7 after surgery $(n=3$ in each group at each time point). Another three mice were sacrificed without any treatment to serve as naïve nonsurgery control. To isolate total ribonucleic acid (RNA), central portion of quadriceps muscle was removed from animals immediately after scarification and were homogenized in $500 \mu \mathrm{L}$ of Trizol reagent (Life Technologies; Grand Island, New York) according to the manufacturer's instructions. Isolated RNA was quantified and normalized to synthesize complementary deoxyribonucleic acid. Reverse transcript polymerase chain reaction (RT-PCR) was performed to quantify the expression of genes in muscle samples using a SYBR Green I master kit (Roche Diagnostics Corp; Indianapolis, Indiana). Gene expression was normalized to glyceraldehyde 3-phosphate dehydrogenase, a housekeeping gene. Fold change was calculated by using a $\Delta \Delta$ computed tomography method.

\section{Statistical Analysis}

Student $t$-test was used to compare the HO bone volume (BV) between the SCI and control groups. Quantitative polymerase chain reaction data are presented as fold change \pm standard error. Significance is defined as $p<0.05$.

\section{RESULTS}

\section{Bone Morphogenetic Protein-2 Induces Significant Heterotopic Ossification in Hind Limbs of Mice with Spinal Cord Injury}

MicroCT scanning showed significant amount of mineral deposition in the hind limbs in mice with SCI. Figure 1 presents typical microCT images of HO. Quantitative analysis of BV of $\mathrm{HO}$ in the hind-limb microCT scanning showed that $0.50 \mu \mathrm{g}$ of BMP-2 causes $1.12 \pm$ $0.03 \mathrm{~mm}^{3}$ (mean \pm standard error) ectopic bone in the 


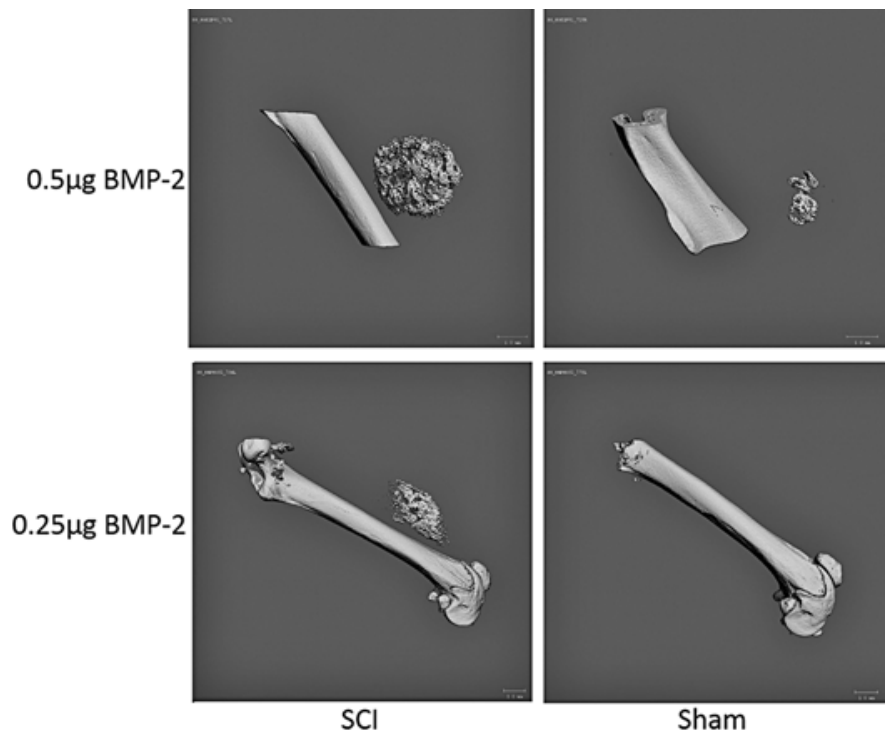

Figure 1.

Typical microcomputed tomography images of heterotopic ossification ( $\mathrm{HO}$ ) induced by 0.50 and $0.25 \mu \mathrm{g}$ of bone morphogenetic protein (BMP)-2 in mice after spinal cord injury ( $\mathrm{SCl}$ ) and sham surgery. $0.50 \mu \mathrm{g}$ of BMP-2 induced large amount of $\mathrm{HO}$ in quadriceps muscle in mice with $\mathrm{SCl}$ but only induced small amount of $\mathrm{HO}$ in mice with sham surgery. $0.25 \mu \mathrm{g}$ of BMP-2 induced $\mathrm{HO}$ in mice with $\mathrm{SCl}$ but not in mice with sham surgery.

quadriceps muscle of mice with SCI and $0.08 \pm 0.03 \mathrm{~mm}^{3}$ ectopic bone in the quadriceps muscle of control mice. The $t$-test showed that $0.50 \mu \mathrm{g}$ of BMP-2 causes significantly more $\mathrm{HO}$ in the quadriceps muscles of mice that underwent SCI than in control mice $(p=0.02, n=4)$. $0.25 \mu \mathrm{g}$ of BMP-2 causes $0.61 \pm 0.09 \mathrm{~mm}^{3}(n=4)$ ectopic bone in the quadriceps muscle in mice with SCI but does not cause notable $\mathrm{HO}$ in the quadriceps muscles of control mice $(n=4)$ (Figure 2). Hydrogel alone did not cause notable $\mathrm{HO}$ in the quadriceps muscles in either SCI or control groups $(n=4)$ (images not shown). This result suggests that BMP-2 at the dose of $0.25 \mu \mathrm{g}$ only induces $\mathrm{HO}$ in mice with SCI.

\section{Bone Morphogenetic Protein-2 Induces Significant Heterotopic Ossification in Fore Limbs of Mice with Spinal Cord Injury}

Hydrogel carrier with $0 \mu \mathrm{g}$ of BMP-2 did not induce any $\mathrm{HO}$ in either mice with SCI or control mice (image not shown). Interestingly, $0.25 \mu \mathrm{g}$ of BMP-2 induced significant $\mathrm{HO}$ in the triceps muscle of the fore limb in six of the eight limbs from mice with SCI (75\%). However, the same dose of BMP-2 did not induce notable HO in the triceps muscle in any of the eight limbs of the control mice $(0 \%)$. Figure 3 presents a typical picture of $\mathrm{HO}$ in the fore limbs. This result suggests that SCI-induced HO is not limited to paralyzed muscle.

\section{Spinal Cord Injury Induces Well-Organized Heterotopic Ossification with Bone Morphogenetic Protein-2 Induction}

H\&E staining of the spinal cord showed that the impaction injury causes severe damage to the spinal cord. Necrotic tissue with severe inflammation cell infiltration was seen in the injury site of the spinal cord (Figure 4). H\&E staining for the hind-limb sections showed that $0.25 \mu \mathrm{g}$ of BMP-2 induced well-differentiated ectopic bone in the quadriceps muscle in the mice with SCI, which is similar to the $\mathrm{HO}$ seen in patients. However, the injection with the same amount of BMP-2 only causes focal muscle damage with fibrotic degradation in the control mice. No osseous tissue was found (Figure 5).

\section{Increase in Bone Morphogenetic Protein Signaling Following Spinal Cord Injury}

BMP-2, BMP-4, BMP-7, and BMP-9 expression was significantly increased at the messenger RNA level in quadriceps of mice that underwent SCI (Figures 6-7). No significant difference was seen in expression of BMP receptors 1a and 2 and noggin between mice with SCI and control mice following $3 \mathrm{~d}$.

\section{DISCUSSION}

We have successfully developed a new murine model of SCI-induced HO that mimics the formation of heterotopic bone associated with SCI seen clinically. A subthreshold dose of BMP-2 at $0.25 \mu \mathrm{g}$ successfully induces $\mathrm{HO}$ in mice after SCI but not in mice that underwent sham surgery.

To our knowledge, this is the first SCI-induced $\mathrm{HO}$ mouse model ever reported. Though a subthreshold dose of $0.25 \mu \mathrm{g}$ BMP-2 is required, $\mathrm{SCI}$ is still the driving force for the development of $\mathrm{HO}$ in this model, since no $\mathrm{HO}$ is observed in the control group with the dose of BMP-2 injection. This novel mouse model may help to explore the etiology and pathophysiology of SCI-induced HO. It may also serve as a powerful tool in the development 

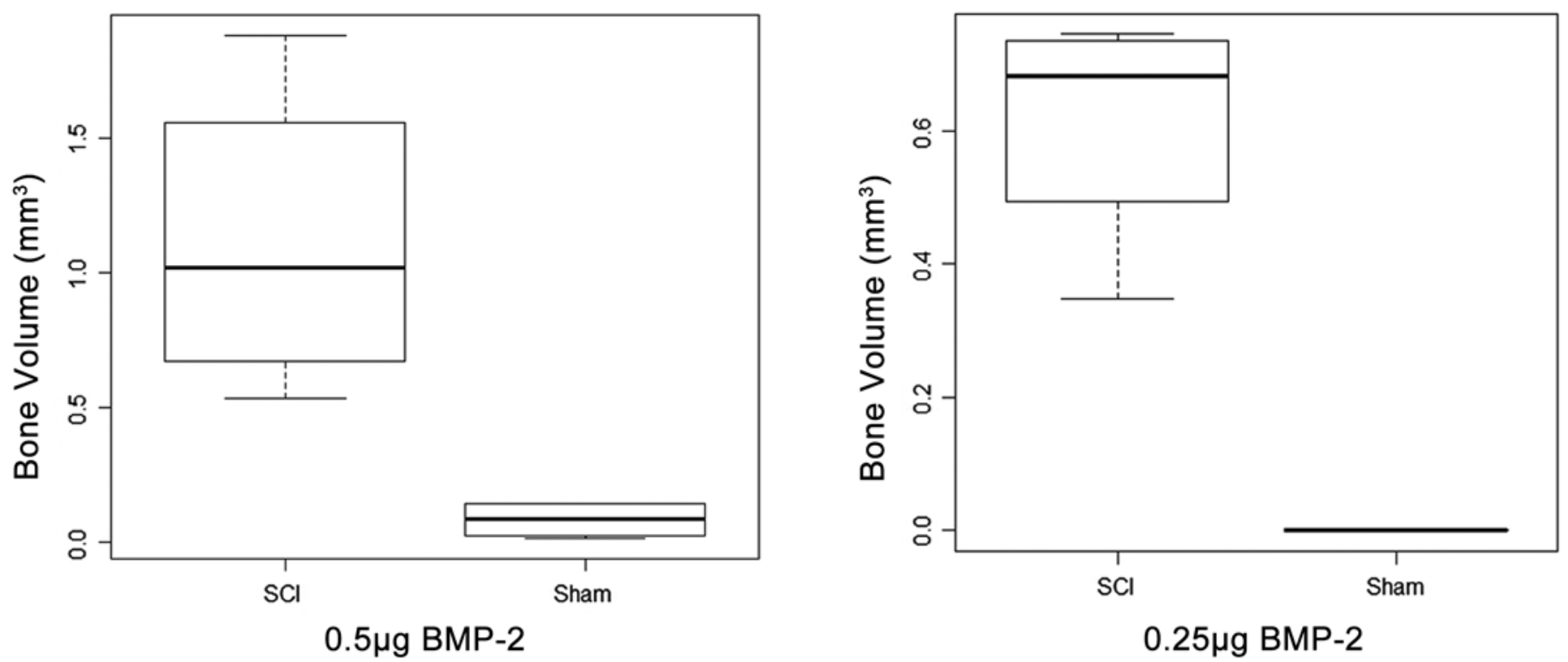

Figure 2.

Quantification of bone volume (BV) of heterotopic ossification (HO) in mice with spinal cord injury (SCl) and sham surgery induced by 0.50 and $0.25 \mu \mathrm{g}$ of bone morphogenetic protein (BMP)-2. BV of $\mathrm{HO}$ in mice with SCl was significantly greater than that in mice with sham surgery with induction of $0.50 \mu \mathrm{g} \mathrm{BMP}-2(p=0.02, n=4) .0 .25 \mu \mathrm{g}$ of BMP-2 only induced $\mathrm{HO}$ in mice with SCl.

of new prevention and treatment strategies following SCI-induced HO.

Our model parallels the clinical and laboratorial changes observed in patients with SCI that develop HO. Clinically, HO typically develops rapidly (within 2-6 mo)

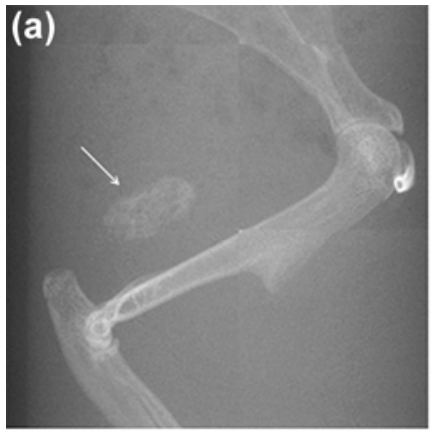

$\mathrm{SCl}$

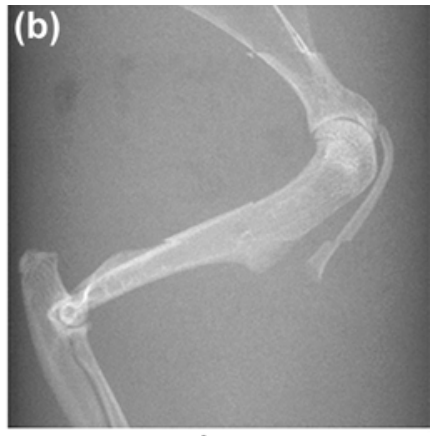

Sham
Figure 3.

Typical picture of microcomputed tomography scoutview picture of fore limbs from (a) mice with spinal cord injury (SCI) and (b) mice with sham surgery $2 \mathrm{wk}$ after receiving $0.25 \mu \mathrm{g}$ of bone morphogenetic protein (BMP)-2 injection in triceps muscle. $0.25 \mu \mathrm{g}$ of BMP-2 induced significant heterotopic ossification in triceps muscle in mice with $\mathrm{SCl}$ (arrow) but not in mice with sham surgery. in patients with SCI. Similarly, in our model, HO developed as soon as $2 \mathrm{wk}$ after surgery. This lap time is consistent with the lap time seen in patients with SCI considering the difference of life span between mice and humans. Histologically and radiographically, intramuscular $\mathrm{HO}$ is distinguished from simple muscle calcification by the growth of mature lamellar bone with robust osteoblasts inside the muscle. Our histological analysis showed formation of differentiated lamella bone with a large amount of osteoblasts and osteocytes at the $\mathrm{HO}$ site. This again

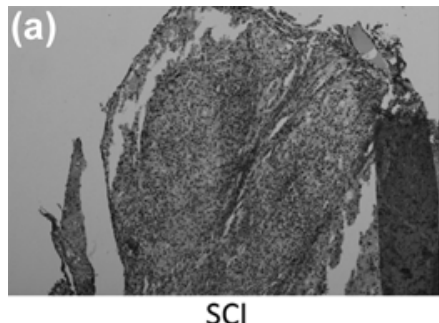

$\mathrm{SCl}$

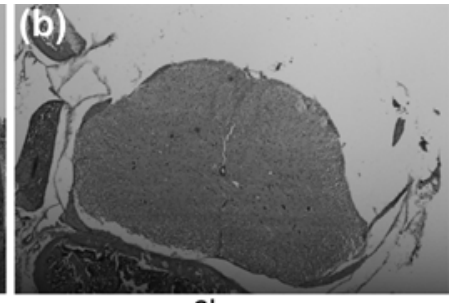

Sham
Figure 4.

Typical images of hematoxylin and eosin staining of spinal cord from (a) mice with spinal cord injury and (b) mice with sham surgery 2 wk after surgery. One-time impaction injury caused massive necrosis and inflammation cell infiltration in spinal cord. 

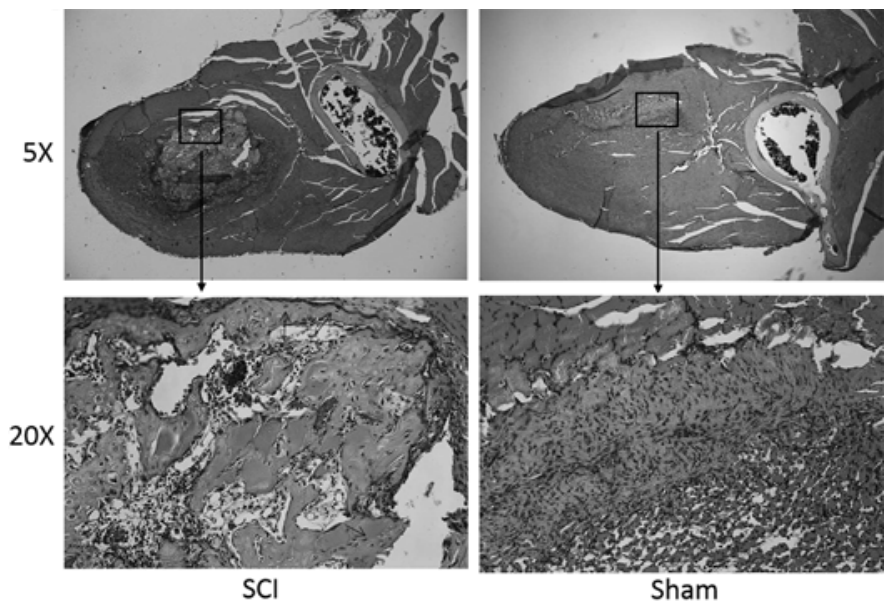

Figure 5.

Typical image of hematoxylin and eosin staining of midsection of thigh from mice with spinal cord injury $(\mathrm{SCl})$ and mice with sham surgery 2 wk after receiving $0.25 \mu \mathrm{g}$ of bone morphogenetic protein (BMP)-2 injection. $0.25 \mu \mathrm{g}$ of BMP-2 induced significant heterotopic ossification with similar size as femur bone in mice with $\mathrm{SCl}$. Well-differentiated ectopic bone in quadriceps muscle in mice with $\mathrm{SCl}$ possessed mature lamellar bone and large amount of osteoblasts and osteocytes (arrows). However, injection with same amount of BMP-2 only caused focal muscle damage with fibrotic degradation in mice with sham surgery. No osseous tissue was found.

suggests that the HO developed in our mouse model is consistent with that seen in patients with SCI.

Previous work has suggested that BMP signaling may be a key player in the development of HO. One extreme example is the development of massive $\mathrm{HO}$ in fibrodysplasia ossificans progressive patients, in whom a mutation in BMP receptor, activin receptor-like kinase-2, results in automatic activation of BMP signaling. In our work, we have observed significantly increased expression of BMP ligands in the quadriceps muscle after SCI, suggesting that upregulated intrinsic BMP signaling may be involved in $\mathrm{HO}$ development following SCI. In our model, it seems that SCI increases BMP ligand expression instead of BMP receptor expression. The expression of noggin, an intrinsic BMP inhibitor, was not changed.

Previous studies, including our own experiments, have shown that spontaneous $\mathrm{HO}$ is extremely difficult to induce in mice without osteoinductive stimulation. Unlike in humans, mice do not generate spontaneous HO after SCI. This suggests that osteoinductive signals fol-

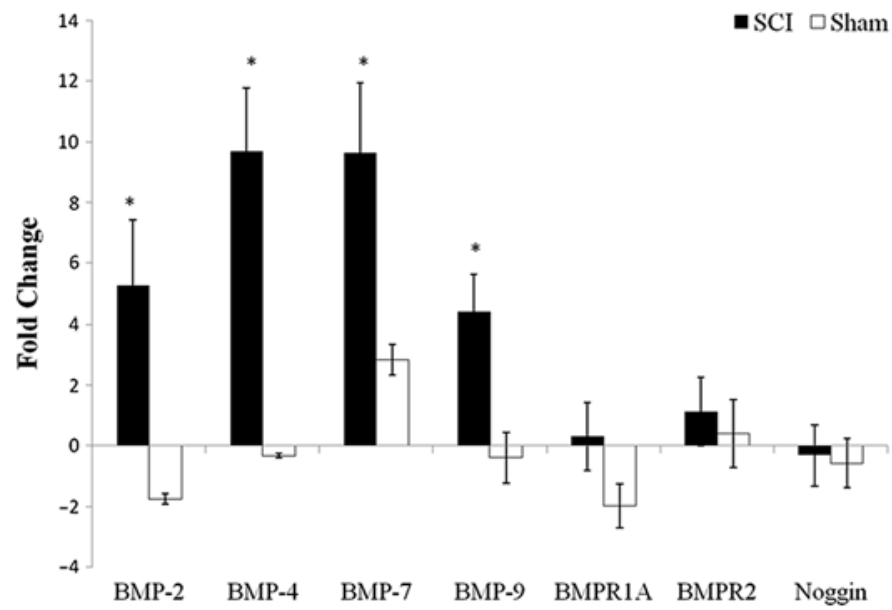

Figure 6.

Fold change of bone morphogenetic protein (BMP)-2, BMP-4, BMP-7, BMP-9, BMP receptors $1 \mathrm{a}$ and 2 , and noggin in quadriceps after $3 \mathrm{~d}$ in mice that underwent spinal cord injury (SCl) and sham surgery with no BMP-2 injection $\left({ }^{*} p<0.05\right)$.

lowing SCI may not be strong enough to solely induce spontaneous HO in mice. A secondary boosting signal, such as a subthreshold dose of BMP-2 as used in our study, is required to induce $\mathrm{HO}$ formation in mice following $\mathrm{SCI}$.

Our results from examining mouse fore limbs showed that a subthreshold dose of BMP-2 can also

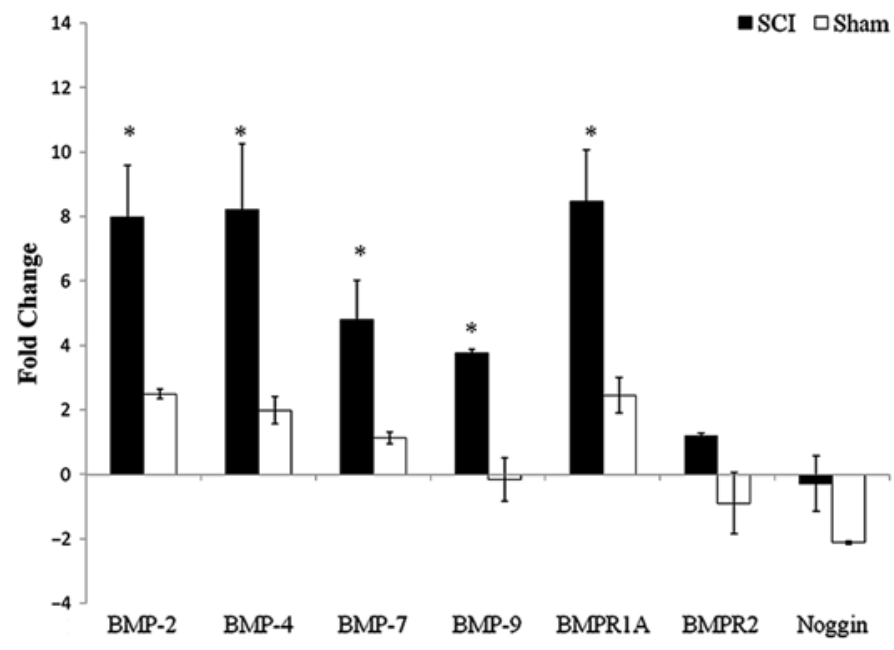

Figure 7.

Fold change of bone morphogenetic protein (BMP)-2, BMP-4, BMP-7, BMP-9, BMP receptors $1 \mathrm{a}$ and 2 , and noggin in quadriceps after $7 \mathrm{~d}$ in mice that underwent spinal cord injury (SCI) and sham surgery with no BMP-2 injection $\left({ }^{*} p<0.05\right)$. 
induce significant HO in mice after SCI. Since SCI took place at the T10 level, the sensory and motor functions of the fore limbs in those mice were not impaired. This result suggests that paralysis is not required for muscle to develop HO after SCI. This finding is consistent with the clinical finding of $\mathrm{HO}$ developed at the elbow joints in patients with thoracic and lumbar SCI. Though the exact mechanism remains unknown, it seems like SCI may lead to systematic hormonal changes that sensitize the muscles to osteoinductive signals and, thus, stimulate the development of HO. Future work is needed to determine the hormonal signals induced by SCI.

In this study, we chose spinal process removal instead of laminectomy as the sham surgery. This is because exposure of spinal cord during laminectomy increases the risk of minor cord injury during spinal cord exposure. Spinal process removal generates the same amount of muscular and bony injury as seen in our SCI surgery while keeping the spinal canal intact. Thus, we believe this is an appropriate and safe sham surgery for this study.

There are several limitations to our model. First, HO development in our model is BMP-2-dependent. However, we believe that such a small dose of BMP-2 may only serve as a "booster" of osteoinductive signal instead of eliciting HO formation. This is evident by our RT-PCR results, which demonstrate upregulation of intrinsic BMP-2 and other BMPs in muscle after SCI. Additional BMP-2 we injected into the mouse muscle may have solely amplified intrinsic BMP signaling following SCI. Second, the location of $\mathrm{HO}$ in our model is different from that observed in patients with SCI. Clinically, HO is most commonly seen near the hip or elbow joints in patients with SCI. However, the BV of HO near the joints is technically difficult to quantify using microCT scanning due to the small size of the mouse. In our model, HO is mainly present in the middle of the quadriceps muscle, where BMP-2 was injected. We chose to inject BMP-2 at the center of the quadriceps because $\mathrm{HO}$ formed there is far away from the femur and hip joint. Thus, the HO developed in our model is a "pure" intramuscular HO, which is easy to quantify with microCT scanning. Third, we only evaluated $\mathrm{HO}$ BV at a single time point- $2 \mathrm{wk}$ after BMP-2 injection in this study. This time point was chosen based on the time course of BMP-2-induced HO we tested in C57/BL6 mice previously [16], in which we found that HO develops no later than 2 wk after BMP-2 injection. However, the mice we used for the previous time course study did not receive surgeries. Thus, the time course of BMP-2-induced HO in mice with SCI and control mice may have small deviations. Future works may be needed to prove the time course of BMP-2induced HO in mice with SCI. Last, we only chose BMP signaling for gene expression analysis, while other osteogenic signaling (like Wnt signaling) may also be involved in HO. Future works are deserved to fully reveal osteogenic pathways involved in HO.

\section{CONCLUSIONS}

In this study, we have developed a novel SCIinduced HO mouse model that mimics the HO seen clinically. This model may serve as a powerful tool in developing novel prevention and treatment strategies for SCIinduced HO.

\section{ACKNOWLEDGMENTS}

\section{Author Contributions:}

Study concept and design: X. Liu, B. Halloran, R. Nissenson, X. Zhang, J. Li, H. T. Kim.

Analysis and interpretation of data: H. Kang, A. B. Dang, S. K. Joshi. Drafting of manuscript: X. Liu.

Conducted experiments: H. Kang, A. Dang, S. Joshi, X. Liu.

Financial Disclosures: The authors have declared that no competing interests exist.

Funding/Support: This material was based on work supported by the Department of Defense (grant W81XWH-11-2-0189), Department of Veterans Affairs (VA) Rehabilitation Research and Development Merit Review (grant RX000195), and the Northern California Institute for Research and Education. We thank Drs. Olla Larm and Lars Adolfsson (ExThera AB; Stockholm, Sweden) for their kind gift of heparin-chitosan hydrogel.

Additional Contributions: We thank Dr. Liping Wang at the San Francisco VA Medical Center for his advice on experiment design. We also thank Mr. Alfred Li at the San Francisco VA Medical Center Bone Core Facility for his technical support in microCT scanning and analysis. Ms. Kang is currently an $\mathrm{MD} / \mathrm{PhD}$ student with the Medical Scientist Training Program, University of Pittsburgh School of Medicine, Pittsburgh, Pennsylvania.

Institutional Review: All animal procedures were approved by the Institutional Animal Care and Use Committee at the San Francisco VA Medical Center. 


\section{REFERENCES}

1. Kaplan FS, Glaser DL, Hebela N, Shore EM. Heterotopic ossification. J Am Acad Orthop Surg. 2004;12(2):116-25. [PMID:15089085]

2. Garland DE. A clinical perspective on common forms of acquired heterotopic ossification. Clin Orthop Relat Res. 1991;(263):13-29. [PMID:1899635]

3. Potter BK, Burns TC, Lacap AP, Granville RR, Gajewski DA. Heterotopic ossification following traumatic and combat-related amputations. Prevalence, risk factors, and preliminary results of excision. J Bone Joint Surg Am. 2007; 89(3):476-86. [PMID:17332095] http://dx.doi.org/10.2106/JBJS.F.00412

4. Forsberg JA, Pepek JM, Wagner S, Wilson K, Flint J, Andersen RC, Tadaki D, Gage FA, Stojadinovic A, Elster EA. Heterotopic ossification in high-energy wartime extremity injuries: Prevalence and risk factors. J Bone Joint Surg Am. 2009;91(5):1084-91. [PMID:19411456] http://dx.doi.org/10.2106/JBJS.H.00792

5. Cipriano CA, Pill SG, Keenan MA. Heterotopic ossification following traumatic brain injury and spinal cord injury. J Am Acad Orthop Surg. 2009;17(11):689-97. [PMID:19880679]

6. Sullivan MP, Torres SJ, Mehta S, Ahn J. Heterotopic ossification after central nervous system trauma: A current review. Bone Joint Res. 2013;2(3):51-57.

[PMID:23610702]

http://dx.doi.org/10.1302/2046-3758.23.2000152

7. Hurvitz EA, Mandac BR, Davidoff G, Johnson JH, Nelson VS. Risk factors for heterotopic ossification in children and adolescents with severe traumatic brain injury. Arch Phys Med Rehabil. 1992;73(5):459-62. [PMID:1580774]

8. Hendricks HT, Geurts AC, van Ginneken BC, Heeren AJ, Vos PE. Brain injury severity and autonomic dysregulation accurately predict heterotopic ossification in patients with traumatic brain injury. Clin Rehabil. 2007;21(6):545-53. [PMID:17613585] http://dx.doi.org/10.1177/0269215507075260

9. Dizdar D, Tiftik T, Kara M, Tunç H, Ersöz M, Akkuş S. Risk factors for developing heterotopic ossification in patients with traumatic brain injury. Brain Inj. 2013;27(7-8): 807-11. [PMID:23730889]

http://dx.doi.org/10.3109/02699052.2013.775490

10. Sakellariou VI, Grigoriou E, Mavrogenis AF, Soucacos PN, Papagelopoulos PJ. Heterotopic ossification following traumatic brain injury and spinal cord injury: Insight into the etiology and pathophysiology. J Musculoskelet Neuronal Interact. 2012;12(4):230-40. [PMID:23196266]

11. Biering-Sørensen F, Burns AS, Curt A, Harvey LA, Jane Mulcahey M, Nance PW, Sherwood AM, Sisto SA. International spinal cord injury musculoskeletal basic data set.
Spinal Cord. 2012;50(11):797-802. [PMID:22945748]

http://dx.doi.org/10.1038/sc.2012.102

12. Schoenfeld AJ, Laughlin MD, McCriskin BJ, Bader JO, Waterman BR, Belmont PJ Jr. Spinal injuries in United States military personnel deployed to Iraq and Afghanistan: An epidemiological investigation involving 7877 combat casualties from 2005 to 2009. Spine. 2013;38(20):1770-78. [PMID:23759821]

13. Genêt F, Jourdan C, Lautridou C, Chehensse C, Minooee K, Denormandie P, Schnitzler A. The impact of preoperative hip heterotopic ossification extent on recurrence in patients with head and spinal cord injury: A case control study. PLoS ONE. 2011;6(8):e23129. [PMID:21853078] http://dx.doi.org/10.1371/journal.pone.0023129

14. Baldwin K, Hosalkar HS, Donegan DJ, Rendon N, Ramsey M, Keenan MA. Surgical resection of heterotopic bone about the elbow: An institutional experience with traumatic and neurologic etiologies. J Hand Surg Am. 2011;36(5): 798-803. [PMID:21458925] http://dx.doi.org/10.1016/j.jhsa.2011.01.015

15. O'Connor JP. Animal models of heterotopic ossification. Clin Orthop Relat Res. 1998;(346):71-80. [PMID:9577413]

16. Liu X, Kang H, Shahnazari M, Kim H, Wang L, Larm O, Adolfsson L, Nissenson R, Halloran B. A novel mouse model of trauma induced heterotopic ossification. J Orthop Res. 2014;32(2):183-88. [PMID:24136593] http://dx.doi.org/10.1002/jor.22500

17. Ling X, Liu D. Temporal and spatial profiles of cell loss after spinal cord injury: Reduction by a metalloporphyrin. J Neurosci Res. 2007;85(10):2175-85. [PMID:17551979] http://dx.doi.org/10.1002/jnr.21362

18. Bradbury EJ, Moon LD, Popat RJ, King VR, Bennett GS, Patel PN, Fawcett JW, McMahon SB. Chondroitinase ABC promotes functional recovery after spinal cord injury. Nature. 2002;416(6881):636-40. [PMID:11948352] http://dx.doi.org/10.1038/416636a

19. Dang AB, Tay BK, Kim HT, Nauth A, Alfonso-Jaume MA, Lovett DH. Inhibition of MMP2/MMP9 after spinal cord trauma reduces apoptosis. Spine. 2008;33(17):E576-79. [PMID:18670324] http://dx.doi.org/10.1097/BRS.0b013e31817ecc87

20. Engstrand T, Veltheim R, Arnander C, Docherty-Skogh AC, Westermark A, Ohlsson C, Adolfsson L, Larm O. A novel biodegradable delivery system for bone morphogenetic protein-2. Plast Reconstr Surg. 2008;121(6):1920-28. [PMID: 18520877] http://dx.doi.org/10.1097/PRS.0b013e31817151b0

Submitted for publication January 25, 2014. Accepted in revised form April 21, 2014. 
This article and any supplementary material should be cited as follows:

Kang H, Dang AB, Joshi SK, Halloran B, Nissenson R, Zhang X, Li J, Kim HT, Liu X. Novel mouse model of spinal cord injury-induced heterotopic ossification. J Reha- bil Res Dev. 2014;51(7):1109-18.

http://dx.doi.org/10.1682/JRRD.2014.01.0019

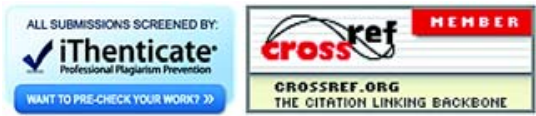


